\title{
The Stepped Care Intervention to Suppress Viral Load in Youth Living With HIV: Protocol for a Randomized Controlled Trial
}

Elizabeth Mayfield Arnold ${ }^{1}$, MSW, PhD; Dallas Swendeman², PhD; Danielle Harris ${ }^{2}$, MA, MPH; Jasmine Fournier ${ }^{3}$, MS; Leslie Kozina ${ }^{3}$, CCRC; Susan Abdalian ${ }^{3}$, MD; Mary Jane Rotheram ${ }^{2}$, PhD; Adolescent Medicine Trials Network CARES Team

\footnotetext{
${ }^{1}$ Department of Family and Community Medicine, UT Southwestern Medical Center, Dallas, TX, United States

${ }^{2}$ Department of Psychiatry and Biobehavioral Sciences, University of California, Los Angeles, Los Angeles, CA, United States

${ }^{3}$ Section of Adolescent Medicine, Department of Pediatrics, Tulane University, New Orleans, LA, United States
}

\section{Corresponding Author:}

Elizabeth Mayfield Arnold, MSW, PhD

Department of Family and Community Medicine

UT Southwestern Medical Center

5959 Harry Hines Blvd, POB 1, Suite 720

Dallas, TX, 75390-9194

United States

Phone: 12146488140

Email: liz.arnold@utsouthwestern.edu

\section{Abstract}

Background: Among youth living with HIV (YLH) aged 12-24 years who have health care in the United States, only $30 \%$ to $40 \%$ are virally suppressed. YLH must achieve viral suppression in order to reduce the probability of infecting others as well as increasing the length and quality of their own life.

Objective: This randomized controlled trial aimed to evaluate the efficacy of an Enhanced Standard Care condition ( $\mathrm{n}=110$ ) compared to an Enhanced Stepped Care intervention condition $(n=110)$ to increase viral suppression among YLH aged 12-24 years with established infection (not acutely infected).

Methods: YLH (N=220) who are not virally suppressed will be identified at homeless shelters, health clinics, and gay-identified community-based organizations in Los Angeles, CA, and New Orleans, LA. Informed consent will be obtained from all participants. YLH will be randomly assigned to one of two study conditions: Enhanced Standard Care, which includes standard clinical care plus an automated messaging and monitoring intervention (AMMI), or an Enhanced Stepped Care, which includes three levels of intervention (AMMI, Peer Support via social media plus AMMI, or Coaching plus Peer Support and AMMI). The primary outcome is viral suppression of HIV, and YLH will be assessed at 4-month intervals for 24 months. For the Enhanced Stepped Care intervention group, those who do not achieve viral suppression (via blood draw, viral load<200 copies/mL) at any 4-month assessment will "step up" to the next level of intervention. Secondary outcomes will be retention in care, antiretroviral therapy adherence, alcohol use, substance use, sexual behavior, and mental health symptoms.

Results: Recruitment for this study began in June 2017 and is ongoing. We estimate data collection to be completed by the end of 2020 .

Conclusions: This is the first known application of an Enhanced Stepped Care intervention model for YLH. By providing the lowest level of intervention needed to achieve viral suppression, this model has the potential to be a cost-effective method of helping YLH achieve viral suppression and improve their quality of life.

Trial Registration: ClinicalTrials.gov NCT03109431; https://clinicaltrials.gov/ct2/show/NCT03109431

International Registered Report Identifier (IRRID)： DERR1-10.2196/10791

(JMIR Res Protoc 2019;8(2):e10791) doi: 10.2196/10791

\section{KEYWORDS}

HIV seroposivity; adolescent; young adult; sustained virologic responses 


\section{Introduction}

\section{Background}

New diagnoses of HIV among youth aged 12-24 years continue to be a challenging public health problem in the United States $[1,2]$, with one in four new HIV diagnoses and 60,900 youth living with HIV (YLH) [3]. The substantial improvements in scientists' ability to prevent and treat HIV infection [4,5] are underutilized by YLH. Similar to adults, if a YLH has an undetectable viral load, there is a $94 \%$ likelihood of not transmitting HIV [6] and the YLH is likely to live longer [7] and have a better quality of life [8]. Furthermore, only $30 \%$ to $44 \%$ of those diagnosed are virally suppressed $[2,9]$. This study evaluates a Stepped Care model to support YLH to achieve viral suppression.

YLH are concentrated in areas of the United States where the epidemic has grown, with certain groups disproportionately impacted, particularly in the South [10]. Black and Latino men-who-have-sex-with-men are at the highest risk for new HIV infections [11]. Among youth diagnosed with HIV, 81\% are gay, bisexual, and transgender youths (GBTY), with the highest rates reported among black and Hispanic/Latino men [2]. GBTY coming of age today may not perceive the same risk of premature death, which characterized young men earlier in the epidemic when there were fewer treatment options.

It is imperative that YLH achieve viral suppression in order to reduce the probability of infecting others as well as increase the length and quality of their lives [7,8]. Among YLH, viral suppression requires linkage and retention in care as well as antiretroviral therapy (ART) adherence. As part of the HIV Treatment Continuum [12], YLH must overcome all barriers to seeking and receiving medical care and then adhere daily to their ART $[1,13]$. Historically, achieving an undetectable viral load required 95\% ART adherence [14]. However, rates as low as $80 \%$ may lead to viral suppression [15]; at present, the pills are combined in regimens and ART is more robust. The duration of "drug holidays" (ie, days without medication) is at least as important as the number of pills taken as prescribed when monitoring adherence that aims to result in an undetectable viral load [16]. However, even with only an $80 \%$ adherence rate required for viral suppression and the typical regimen consisting of only one pill daily, YLH are far from meeting this target.

Retention in care and adherence to ART are related. Although $41 \%$ of YLH know their serostatus, only $62 \%$ receive medical care within 12 months of diagnosis [1]. Retention rates can be low, with only one in four YLH retained in care at 3 years after treatment initiation [17]. Among one sample of YLH (atypically, $72 \%$ women), initial ART adherence was $69 \%$, but by 1 year, ART adherence was negligible, partly due to only a $30 \%$ retention in HIV care [18]. Young people are also more likely to dropout from care than middle-aged and older adults $[13,19]$. Existing studies suggest that few YLH remain in medical care more than a year, ensuring that ART treatment adherence will also be low [20-22].

\section{Barriers to Adherence Among Youth Living With HIV}

In addition to connecting YLH to care, it is important to identify and address barriers to adherence. Others have suggested that targeting patient group characteristics to improve adherence may not be the answer, but instead, focusing on individual needs with the flexibility to address specific identified barriers may be helpful [23]. Barriers can be structural issues, and many of the challenges to adherence faced by YLH are interrelated. Drawing upon the work of Maslow [24], Barroso and colleagues assert that people living with HIV must first have their basic biological and physiological needs met to become adherent, including food and transportation, and there must be a focus on reducing stigma and addressing community-level barriers that contribute to disparities [25]. Psychological issues can be part of this complex problem, and even forgetting to take one's medication can be due to the lack of a set routine or a more complex process that involves cognitive or behavioral struggles [26]. Shame as well as mental health problems and substance abuse may also contribute to delayed medication initiation and difficulties with adherence [27]. Thus, it is important that interventions targeting viral suppression have the flexibility to address multiple factors in the lives of YLH.

\section{Intervention Innovation of the Protocol: Stepped Care}

Stepped Care is a strategy used in managing chronic diseases and mental health problems [28-30], but has only recently been applied to YLH in one trial [31]. Using a Stepped Care approach, providers implement the least intensive intervention needed to achieve the treatment goal and intensify the intervention until the treatment goal is achieved. With this Stepped Care framework, this study will implement a low-intensity intervention, followed by sequential introduction of more intense and comprehensive interventions. The interventions at the lowest levels require little individual tailoring and may be sufficient for some youth. However, for YLH who do not achieve viral suppression, a more individualized, tailored intervention will be implemented.

Mobile technologies saturate the lives of youth and young adults and offer an opportunity for a variety of interventions. HIV mobile health interventions are a growing area of interest and have been used as interventions for both self-management and medication adherence [32]. One intervention that may be beneficial for Stepped Care models for YLH is an automated messaging and monitoring intervention (AMMI). AMMI interventions using daily text messaging have been shown to be a useful method for medication reminders for HIV-infected individuals [33] and have demonstrated positive effects on medication adherence [34-40] and viral load [41]. We have demonstrated the efficacy of text messaging interventions with various high-risk groups in prior studies [42-46]. In this study, AMMI is based on promoting ART adherence by enhancing self-management of one's care using the concepts of social cognitive theory $[32,47,48]$. Self-management or self-monitoring among persons living with HIV can include reflection, reinforcement of behaviors, and support of cues to action such as taking medications [49]. Peer support is another intervention that is well-suited for use in a Stepped Care model. Positive relationships are a major dimension related to retention in care 
and adherence to ART medications [50-53]. Relationships provide motivation to increase retention in care for a range of other chronic diseases (eg, diabetes, weight reduction, alcohol treatment, and mental health) [54-56]. Although peer support is a component of many evidence-based interventions, there are mixed findings in the meta-analyses conducted on peer support; some found a significant benefit [57,58] and others found a major benefit [59]. Reviews of peer support studies for persons living with HIV, which aimed at reducing stress [60], have found peer support to be a critical intervention component. In particular, adolescence is a developmental period wherein the influence of peers is crucial and has been consistently recognized as an important period from the 1980s [61] to the most recent Lancet reviews on adolescent health determinants [62].

Coaching interventions adapted for YLH are more intensive, individualized interventions that can be used in a Stepped Care model. The roots of coaching can be traced to sports, where a coach, typically working with a group of youths, is a leader who provides guidance, support, and direction. The earliest mention of coaching in the literature was in the 1970s in relation to assertiveness training [63] and later as a method for improving social skills among children [64] and helping families [65] and other types of groups. Since then, coaching has increased in popularity as an alternative to psychotherapy in the business world [66] and as an intervention for a variety of health professionals. Originally done face-to-face, most recently, this type of intervention, commonly known as "health coaching," is also delivered electronically [67]. Coaching has been used as an intervention for chronic pain [68], weight loss [69], HIV medication adherence [70], and other health conditions. A recent review of coaching interventions found positive effects in most studies but highlighted the need for research to be more specific in describing coaching interventions including the types of behavior-change strategies used [71].

\section{Methods}

\section{Overview of Methods and Aims}

As outlined in Figure 1, we will conduct a randomized control trial (RCT) to evaluate the efficacy of an Enhanced Standard Care Intervention $(n=110)$ as compared to an Enhanced Stepped Care Intervention Model $(n=110)$ in order to significantly increase viral suppression among YLH in two cities, Los Angeles, CA, and New Orleans, LA (Trial Registration: ClinicalTrials.gov NCT03109431). This protocol is part of the U19 Research Program Grant that is funded by the Adolescent Medicine Trials Network for HIV/AIDS Interventions (ATN 148; 1U19HD089886).

The specific aims of this study are (1) to assess if Enhanced Standard Care or an Enhanced Stepped Care results in the primary outcome of more sustained viral suppression and improvements in secondary outcomes, (2) to test whether secondary outcomes such as mental health symptoms and drug use mediate the effect of the intervention on viral suppression over time, (3) and to conduct a cost-effectiveness analysis to weigh the benefit of intervention effects on primary and secondary outcomes against intervention implementation costs beyond costs incurred through the standard of care.

All procedures in this study have been approved by the Institutional Review Board of the University of California, Los Angeles, which serves as the single Institutional Review Board of Record for researchers at the collaborating institutions.

\section{Recruitment}

In both New Orleans and Los Angeles, teams of predominantly bachelor's degree-level interviewers aim to screen up to 1500 youths to recruit a cohort of 220 seropositive youths. A description of the study sites in Los Angeles and New Orleans can be found in Rotheram-Borus' and colleagues' article [12].

\section{Inclusion and Exclusion Criteria}

The current inclusion criteria are age of 12-24 years, HIV-positive status, established HIV infection (not acutely infected), and ability to provide informed consent. Exclusion criteria include age under 12 years or above 24 years, HIV-negative status, acute infection with HIV, inability to understand the study procedures due to intoxication or cognitive difficulties (any youth who appears to be under the influence of alcohol or drugs will be unable to enroll in the study but invited to return at a later date), and inability to provide voluntary written informed consent.

\section{Recruitment Procedures}

To identify eligible participants, youth in high-risk settings will be asked to complete a brief screening and rapid HIV test. All screenings are done face-to-face with a study team member from our Recruitment, Engagement, and Retention Center. Older youths (aged 15-24 years) will provide oral consent for the screening, and younger youths (aged 12-14 years) will provide written consent for the screening to ensure that they understand the screening process. Next, all youths aged 12-24 years whose judgment does not appear to be impaired from a disability or substance use will be asked to give written informed consent to complete the screening. Interviewers are trained to assess for problems with cognition, and additional screening questions will be asked if any concerns are identified. To qualify as "eligible" for recruitment, youths must test seropositive on a rapid HIV test and be virally unsuppressed. Based on these screening criteria, eligible youths will be invited to complete the voluntary informed consent (we have a waiver of parental consent for minors). YHL will be randomized to the intervention conditions via the CommCare system (see next section) after viral load results are obtained and entered, which typically takes several days. 
Figure 1. Design of ATN Protocol 148—randomized controlled trial for youth living with HIV (YLH). AMMI: automated messaging and monitoring intervention.

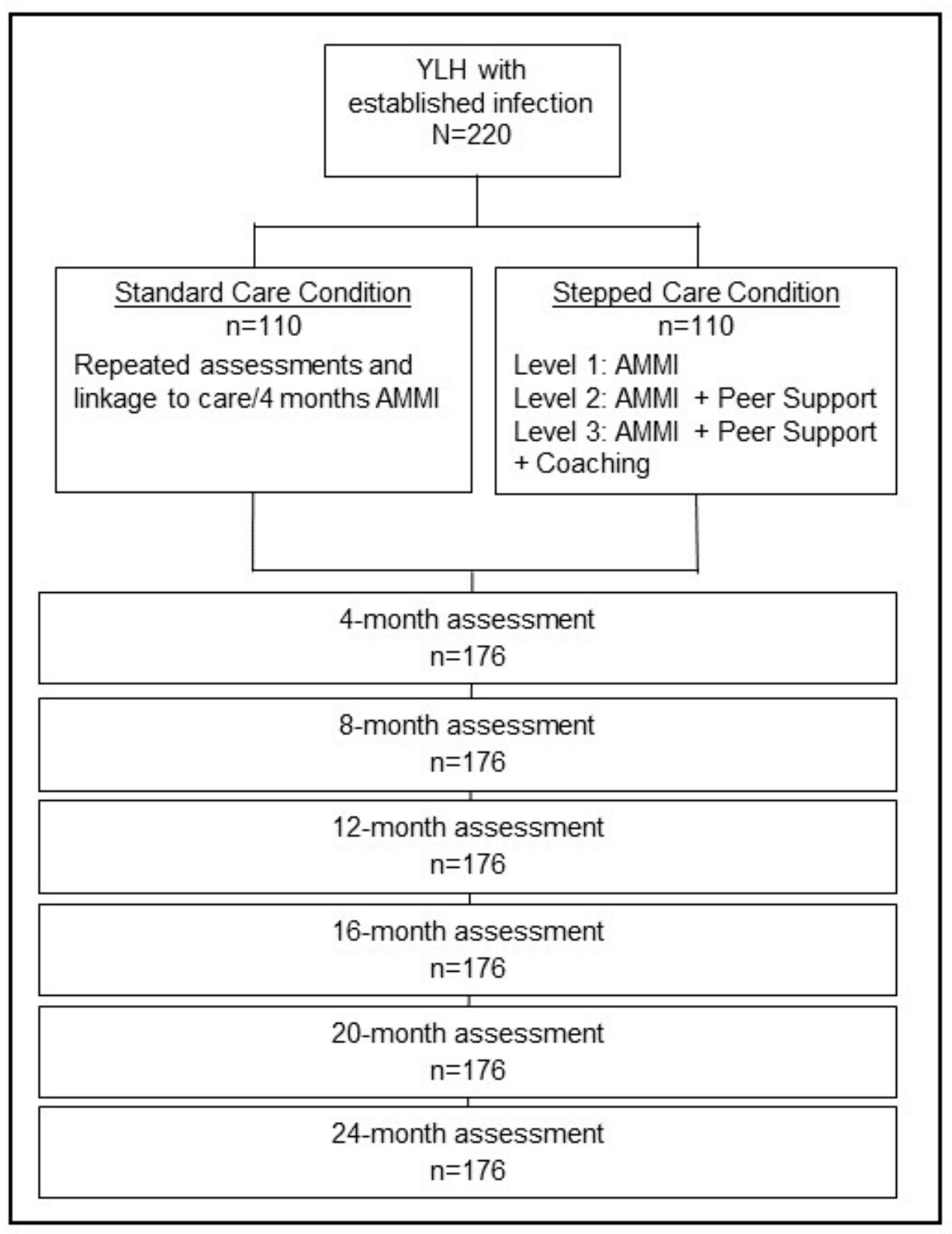

As part of the voluntary informed consent procedures, YHL are asked to provide additional consent to access sensitive information for care coordination and study retention (locating missing participants) for the duration of the study (24 months), which includes their contact information; social media accounts; contact information of their close relatives, friends, and providers including case managers and probation officers; social security number; driver's license or identification card number; and access to their medical records. Providing this additional information is not mandatory, and YLH can refuse to provide these permissions as long as they provide their own contact information; all information will be stored securely in the CommCare system. Only the study team will have access to this information.

\section{Assessments}

Following enrollment, study participants will be asked to complete a baseline assessment, which is administered by the interviewer using Android tablets in approximately 45 minutes.
This assessment covers the following sections: background, risk behaviors, and sociodemographic variables as well as eight cross-cutting domains related to the HIV Treatment Continuum [12]. Interviewers enter the participants' responses in the CommCare system developed by the Dimagi Corporation, Cambridge, MA. CommCare is an open-source, mobile phone-based platform that is cloud based and HIPAA (Health Insurance Portability and Accountability Act) 1996 compliant. This mobile app is used to collect all study data and send out short message service (SMS) messages and weekly surveys as part of AMMI as well as spontaneous broadcast messages for particular groups of participants.

Participants also have a blood draw for viral load monitoring and a series of rapid diagnostic tests (RDTs) which include the following:

- HIV as part of screening: Potential study participants undergo HIV testing using the CLIA-waived Alere 
(Waltham, MA) Determine HIV-1/2 Ag/Ab Combo finger stick blood test for both HIV-1/2 antibodies and the HIV-1 p24 antigen with a window period of 12-26 days, which can be read in 20-30 minutes. Once enrolled in the study, participants also receive HIV testing using the Cepheid (Sunnyvale, CA) Xpert HIV-1 Qual Assay, which is highly sensitive, uses whole blood to detect HIV-1 total nucleic acids, and has a 92-minute read time.

- Chlamydia and Gonorrhea are tested using a Food and Drug Administration-approved Cepheid Xpert CT/NG Assay polymerase chain reaction that is read in 90 minutes.

- Syphilis is tested using the CLIA-waived Syphilis Health Check finger stick blood test to detect treponemal antibodies with a 10 - to 15 -minute read time.

- Hepatitis C is tested using the CLIA-waived OraQuick HCV Rapid Antibody test finger stick blood test with a 20to 40-minute read time.

- $\quad$ Substance use is tested using a multidrug urine test panel to detect the presence of marijuana, cocaine, opiates, and methamphetamine with a 2- to 5-minute read time.

- Alcohol use is assessed using a breathalyzer test that is sensitive for assessing alcohol use in the last 24 hours.

Following completion of the baseline assessment, participants will receive a US $\$ 50$ cash incentive. Any study participant who tests positive for HIV or a sexually transmitted infection (STI) will be offered immediate access to treatment.

\section{Follow-Up Assessments}

Study participants will be reassessed every 4 months over a period of 24 months. In total, the study participants will complete six follow-up assessments and receive a US \$50 cash incentive for each follow-up assessment. Follow-up assessments will include another 45-minute assessment, a blood draw for viral load monitoring, and a series of RDTs for STIs and substance use, as described above. In addition, if study participants report any potential STI symptoms or exposure, they will immediately be offered testing. In between assessments, YLH who need STI testing can use standard care in the community or contact the study team for assistance. At these assessments, participants who are not virally suppressed (viral load<200 copies/mL) will "step up" to the next level of care while still receiving the prior level(s) of care.

\section{Outcome Measures}

\section{Primary Outcome: HIV Viral load}

The primary outcome measure is a suppressed viral load at each 4-month assessment for 24 months. At both sites, whole blood is collected with the anticoagulant EDTA and sent at ambient temperature to an internal laboratory where plasma is separated. In addition, $1.5-3.0 \mathrm{~mL}$ plasma is shipped to an off-site CLIA-certified laboratory to measure viral load by quantitative HIV-1 RNA real time polymerase chain reaction with a level of detection of 20 copies $/ \mathrm{mL}$. Samples from New Orleans are measured at room temperature and those from Los Angeles are measured after they are frozen and thawed. The study team will receive the results through the laboratory's online portal.

\section{Secondary Outcomes}

The following secondary outcomes are also measured at each 4-month assessment for 24 months.

\section{Retention in Care}

YLH are deemed to be retained in care if they attend at least two medical appointments annually. When starting ART, three appointments are scheduled in the first 3 months. Therefore, retention in care also depends on how long YLH have been prescribed ART. We will assess YLH every 4 months; therefore, there are six opportunities over the 24 months of follow-up to obtain self-reports during medical appointments and ensure adherence to ART regimens.

\section{Antiretroviral Therapy Adherence}

ART adherence is based on a Likert scale that asks YLH to rate their ability to take all their HIV medications as prescribed over the prior 30 days. Response categories range from "Very poor" (1) to "Excellent" (6) [72,73].

\section{Alcohol Use Over the Past 4 Months}

This parameter will be assessed using the Alcohol Use Disorders Identification Test, consisting of three questions with Likert-scale responses [74].

\section{Substance Use}

YLH will be asked to indicate if they used any of the following substances over the past 4 months: marijuana, synthetic marijuana, cocaine or crack, heroin, ecstasy, methamphetamines, prescription stimulants or amphetamines, gamma hydroxybutyric acid, ketamine, poppers, inhalants, hallucinogens, prescription painkillers not used as prescribed, and other prescription medications not used as prescribed. YLH will also be asked how many times they injected "drugs such as heroin, opiates, cocaine or amphetamines (crystal)" over the past 4 months. RDTs for alcohol and substance use will be administered to evaluate the degree of underreporting when RDTs indicate use but self-reports do not. Given the fairly short window of detection for RDTs (eg, 24 hours for alcohol), RDTs are not used as outcomes.

\section{Sexual Behavior}

YLH will be asked to report on the following sexual behaviors over the past 4 months: the number of sexual partners (in total and partners who are HIV positive) and the number of insertive and receptive anal sex acts. YLH will also be asked the frequency of condom use with sexual partners at each sexual encounter. Responses categories range from "None of the time" (0) to "All of the time" (5).

\section{Mental Health}

Mental health is assessed using three scales. YLH will be administered four questions from the 12-item Short Form Health Survey [75]. Specifically, they will be asked if they "felt calm and peaceful," had "a lot of energy," and "felt sad and blue" during the past 4 weeks. Response categories range from "None of the time" (0) to "All of the time" (5). YLH are administered the Patient Health Questionnaire for adolescents (PHQ-A) [76], which asks YLH to report how often they were bothered by problems from a list of nine items over the past 2 weeks. Lastly, 
YLH are administered the Generalized Anxiety Disorder 7-item scale [77]. Similar to the PHQ-A, YLH are asked to report how often they were bothered by problems from a list of seven items over the past 2 weeks, such as "Feeling nervous, anxious or on edge."

SMS weekly surveys consist of six items that inquire about how many days YLH felt "sad or depressed;" if they had "any genital itching/pain/discharge, burning during urination, lower stomach pain, or discomfort during sex;" how many times they had sex without using a condom; how many days they used "alcohol and/or drugs;" how many days they did not have a place to sleep; and how many days they missed taking medications. Surveys mainly serve as a tool for research staff to monitor YLH health; check in with them, if needed; and encourage YLH to self-monitor their health and behavior. Items for medication adherence, alcohol/substance use, and sadness/depression will also be treated as outcomes in analyses similar to secondary-outcome analyses. However, low SMS survey-response rates are anticipated based on prior studies with YLH [78]. Therefore, analyses on SMS survey outcomes will be treated as exploratory; precedence will be given to analysis results for secondary outcomes from the 4-month assessment.

\section{Costing}

Costs are of two types: costs of delivering the intervention and additional costs incurred by participants for their use of health care services and services from other agencies. The cost of delivering the intervention requires an estimation of staff time. Coaching logs and other intervention information will be entered into CommCare, which does not provide information regarding the amount of time spent performing study tasks. Thus, staff activity information that is captured by this system will be supplemented by Time It, a mobile app that allows individuals to record the time spent carrying out different staff activities [79]. Each staff member, including program directors, interviewers, and coaches, will record relevant categories of activity over the course of 1 week per quarter. A set of staff activity categories will be prespecified in the mobile app. However, staff are allowed to add more categories as they perform other tasks not previously specified. In addition, personnel time will be estimated from several sources; budgeted time and time recorded on time sheets, for hourly employees, will provide a basis for each staff member's hours devoted to the project.

The costs of additional services are derived from respondent reports of utilization and medical records and will be estimated using publicly available data. Research-specific costs (eg, incentive payments, informed consent, screens, and software adaptation for survey tools) are excluded from the total costs. All cost data will be adjusted for price back to Year 1 of the study by using the medical care component of the consumer price index.

\section{Description of the Intervention}

As shown in Figure 1, the Enhanced Stepped Care condition has three levels of intervention: Level 1, Enhanced Standard Care plus AMMI; Level 2, online peer support via social media plus AMMI plus Enhanced Standard Care; and Level 3, coaching plus online peer support via social media and AMMI plus Enhanced Standard Care. If YLH fail to be virally suppressed (based on analyses of viral load in the blood stream at 4-month intervals), YLH in the Enhanced Stepped Care condition will be provided the next level of intervention in addition to the other levels of care to which they were previously assigned. Note that these interventions overlap with our team's other study of HIV-negative youths and are also described in Swendeman et al [49]. To assess dose of the interventions, we will examine the number of responses to the AMMI surveys (Level 1), the number of peer support posts and logins (Level 2 ), and the number of coaching sessions (Level 3).

\section{Level 1}

Level 1 of the Enhanced Stepped Care model is Enhanced Care plus AMMI. As this is not a medication treatment study, YLH are treated in the community using best practices that are consistent with available treatment guidelines for providers. However, given that YLH have failed to achieve viral suppression with the existing services available to them, we are enhancing standard care by adding an additional component. Thus, Enhanced Care includes existing services received by YHL from health care providers and other agencies as well as daily text messages. Messages for this study focus on five areas: wellness, health care, medication reminders, drug use, and sexual health. We have tailored and adapted preexisting libraries of theoretically based text messages that have been found to be successful in other RCTs with similar populations [80-83], with messages tailored for two different groups-GBTY and non-GBTY. Messages include a focus on empowering YLH (ie, "Don't rely on other people, take your health seriously," and "When you take your meds regularly, you're in control") as well as providing health-related facts ("Meds keep HIV in check" and "Syphilis can increase your viral load"). The goal of AMMI is to target the areas that can impact adherence to ART that will translate into increased rates of viral suppression.

\section{Level 2}

The second level of our Enhanced Stepped Care intervention is a secure, private online/social media peer-support intervention. Participants are invited to participate in an online discussion board through muut.com, an open-source discussion forum that is mobile and desktop friendly. Project staff review access requests to ensure that only participants are attempting to join the board. YLH can personalize their Muut profiles using avatars and (nonidentifying) photos, but cannot choose usernames that compromise their anonymity. Online discussion boards are tailored to topics relevant to youth. Others' experiences with interpersonal group interventions for high-risk youth indicate that group cohesion based on these factors can be a key factor influencing group participation and retention [84,85]. Discussions can be initiated by youth or study team members, including HIV-specific topics related to linkage and retention in care as well as other challenges experienced by YLH.

On all discussion boards, study team members have administrator privileges, allowing them to monitor all activities, post information for discussion, and credit incentives for participants. They take multiple steps to safeguard 
confidentiality and continually review online postings and delete any identifying information posted. Users are removed from the discussion boards if they post inappropriate content three times after receiving feedback for each occurrence, which includes solicitation for sex and drug use; racist, homophobic, or other stigmatizing content; pornographic content; or "trolling" inflammatory remarks or personal insults.

\section{Level 3}

Participants who fail to achieve viral suppression at levels 1 or 2 of the intervention will be assigned to our coaching intervention. Coaching will focus on a variety of risk factors concurrently, as is common in HIV research [86-88], and build on our prior work with this type of intervention. Coaching is based on the strength-based model $[89,90]$ that has demonstrated positive impacts on persons living with HIV [91,92] and HIV prevention $[93,94]$. Identifying and accomplishing goals are critical components of the model. Sessions can be conducted via phone or in person. At the first session, the coach and youth complete a strength assessment that will addresses six main life domains: daily living (survival needs such as food, housing, finances, and employment), physical health (non-HIV-related health problems), health services and health care related to HIV (insurance, linkage to care, ART adherence, viral suppression, treatment cascade, and adherence), social relationships (social support, disclosure, and stigma), mental health (eg, depression, anxiety, and coping), and risks (substance use and risky sexual behaviors). This assessment is used to guide the development of up to three personalized goals with shared responsibility between the youth and coach, depending on the nature of the goals.

After the assessment, sessions will focus on goal attainment. At each session, the coaches use the skills common to $80 \%$ of all child and adolescent evidence-based interventions (EBIs) [95,96]: relaxation, relapse prevention, positive activities/alternatives, referrals, modeling/role playing, positive self-talk, triggers, emotional regulation, monitoring/self-monitoring, support networking/building social support, assertive communication, setting up rewards, problem solving, goal setting, praise, and engagement/rapport building. The use of these skills and their relevance to our coaching intervention are described in further detail in Swendeman et al [49]. The coaching intervention is not manualized but rather relies on the strength assessment, goal setting, and the use of evidence-based skills to develop a personalized plan of intervention for each youth that addresses the unique factors that impact adherence and ultimately, viral suppression. Participation in coaching will continue while the YLH is in the study, but we expect that coaching sessions will decrease in frequency over time as the goals are accomplished.

\section{Selection and Training Coaches}

Our coaching model uses paraprofessionals who have experience and skills in working with the population but do not have advanced degrees [97]. These community members have expertise in addressing the "predictable problems" [98] that these youth experience and will use evidence-based practices to intervene and address specific identified goals [97]. Coaches are also hired based on their interpersonal skills, ability to connect with YLH, and skills in implementing an evidence-based but nonmanualized intervention. They receive intensive training prior to field work to participate in ongoing weekly supervision and have access to real-time supervision in the field.

\section{Data Analyses}

\section{Aim 1}

Intent-to-treat analyses will be used to compare viral suppression as our primary outcome and secondary outcomes between YLH randomized to the Enhanced Stepped Care or Enhanced Standard Care conditions. Comparisons of the same outcomes will also be made between steps in the Enhanced Stepped Care condition as exploratory analyses; the study is only powered for comparisons between study arms. Multilevel models (MLM [99]) will be used to model correlations between repeated observations on the same YLH in order to properly estimate standard errors. Generalized linear MLM will be fit to discrete outcomes such as the binary outcome for viral suppression. MLM fit to the primary outcome for viral suppression will be parameterized to test for the average of viral suppression differences over the follow-up period between study arms (ie, time-averaged effects). This parameterization will be used because all participants are virally unsuppressed at baseline based on eligibility criteria. Secondary outcome levels can differ across study arms; a more standard parameterization that allows for baseline and slope differences over time will be used. We anticipate that randomization will balance out sociodemographic and other important background characteristics across study arms. If characteristics are found to differ across study arms, they will be included as adjustment covariates in MLM. More sophisticated adjustment methods such as propensity scores will be implemented as needed [100]. Data will also be checked for missing data patterns. Appropriate statistical techniques such as multiple imputation will be applied $[98,101]$.

\section{Aim 2}

We will use bivariate-outcome MLM to examine temporal relationships between primary and secondary outcomes. Model parameterization will be based on a number of factors, including visualizations of outcome trajectories and model fit statistics. One parameterization that may be used in a bivariate-outcome MLM is a bivariate random intercept and slope model that we have used in a prior HIV study to examine the time-varying relationship between HIV-transmission behaviors and mental health symptoms [102]. This model is formulated through two separate MLM equations for each outcome that is linked through random effects to model random intercepts and slopes. A variance-covariance matrix is modeled to estimate correlations between random effects. Correlations capture time-varying associations between outcomes such as the correlation between the first outcome at baseline and the second outcome over time and vice versa. The bivariate-outcome model offers a flexible modeling framework to test different mediational models. For example, if the bivariate-outcome model contains outcomes for viral suppression, a secondary outcome such as mental health symptoms, and an intervention effect covariate, then we can test if mental health symptoms mediate the impact of the intervention on viral suppression. Details on bivariate random 
intercept and slope models and other model parameterizations to test for mediational effects in longitudinal data are provided in a previous study [103].

\section{Aim 3}

Cost-effectiveness analyses will be conducted to weigh the benefit of intervention effects on primary and secondary outcomes against intervention implementation costs beyond those incurred through the standard of care. Specifically, analyses will compare the additional cost required, on an average, to obtain an additional unit of outcome in the Enhanced Stepped Care intervention by calculating the cost effectiveness ratio (CER) [104]. The CER is the difference in total costs of providing an Enhanced Stepped Care intervention versus Enhanced Standard Care, divided by the difference in outcomes of Enhanced Stepped and Enhanced Standard Care [104,105]. The primary outcome of viral suppression and secondary outcomes are outcomes of interest. CER is calculated for different combinations of YLH and provider characteristics. We will conduct sensitivity analyses, as recommended by Gold et al [104], to estimate the extent to which the CER calculation is affected by differences in assumptions about the size of the differences in treatment effect. In particular, we will determine how sensitive the CER is to assumptions that the difference in treatment effect is 1 SD below or above the mean estimated effect size. Similarly, we estimate the sensitivity of conclusions to costs that are $1 \mathrm{SD}$ below or above the estimated mean.

\section{Sample Size Calculations}

Sample size calculations are estimated for our primary analysis, which is a comparison of the probability of viral suppression between Enhanced Stepped and Enhanced Standard Care conditions over five time points. The first follow-up is not included in the comparisons because we anticipate that it will take 6 months for improvements in viral suppression to be seen in the Enhanced Stepped Care condition. Based on our proposed sample size of $220(n=110$ in each condition), we anticipate $80 \%$ power for a two-sided test with a .05 alpha level to detect time-averaged percentage differences in viral suppression as small as $9 \%-13 \%$ between conditions. Based on consultation with HIV clinicians, we expect viral suppression rates to be fairly low in the Enhanced Standard Care condition, and we will use a range of rates from $6 \%$ to $20 \%$ in our calculations. Calculations assume a compound symmetry covariance structure. An autocorrelation coefficient is specified to account for correlations between repeated measurements. Calculations are conducted with a range of autocorrelation coefficient values similar to what we have found in prior studies, from .1 to .3. Lastly, we make a conservative assumption of $20 \%$ loss to follow-up so that the sample size in each condition is 88 . In practice, we anticipate a much lower attrition rate. Sample size calculations were carried out using Power Analysis and Sample Size software, version 08.0.11 (Englewood, NJ) [106].

\section{Results}

Recruitment for this study began in June 2017 and is ongoing. We estimate data collection to be completed by the end of 2020 .

\section{Discussion}

This RCT is the first known application of an Enhanced Stepped Care intervention for adolescents and young adults living with HIV. One of the most innovative aspects of this protocol is one that is slightly more difficult to discern: It will provide guidelines on how to implement evidence-based practices, rather than replicating an EBI manual with full fidelity. Although a great deal of progress has been made in secondary prevention with EBI manuals [107], an Enhanced Stepped Care approach requires assessments to uniquely become part of the intervention process when it is time to step up the intervention. There are individual differences in the need for intervention, and there is no need to provide more intervention than is needed. Instead of each YLH receiving the same intervention (as in many EBIs), the dose and type of intervention are linked to outcomes. Training staff in specific skills allows them to apply these skills based on the needs of the youth in a personalized manner that promotes self-management of one's health.

Enhanced Stepped Care is a particularly important model since the funding and resources for HIV care have not increased in recent years. If Enhanced Stepped Care is more successful than the Enhanced Standard Care, this model may be a novel way for others to think about their implementation of a typical EBI. It will be critical to establish cost-effective and diffusible strategies that can be nationally diffused; knowing the cost of the two intervention conditions in this study will be important to inform public policy and the selection of interventions by communities. Without a dramatic reversal, HIV incidence among adolescents is expected to increase, and each additional infection costs US \$379,668 (in 2010) [108]. The Enhanced Stepped Care model proposed in this study is expected to result in better outcomes and cost savings for society by preventing HIV secondary transmission and postponing disease progression. The clinical benefits of Enhanced Stepped Care without increased costs are documented for diabetes [109] and depression [110]; however, data evaluating the cost-effectives of the Stepped Care model for HIV care are lacking. This study will perform an economic evaluation within the RCT and provide valuable data to support the cost-effectiveness of the Enhanced Stepped Care approach in order to enhance HIV treatment and care among YLH groups from both clinical and societal perspectives. If the Enhanced Stepped Care program results in lower or comparable total health care costs relative to usual care, this finding will offer a unique venture point for scaling up the Stepped Care program across the country.

This protocol is particularly relevant to YLH nationally, who typically face challenges of homelessness, mental health problems, school or job issues, contact with the criminal justice system, and risks within their sexual partnerships in addition to their seropositive HIV status. Studies of ART adherence and retention in care have consistently found depression and the types of life challenges young people are experiencing to be directly related to engagement, retention, and adherence to care over time [16,111]. If we fail to address these comorbid issues with YLH, we will not succeed in meeting the goal of viral suppression with YLH. Our Enhanced Stepped Care approach aims to address these issues with increasingly intensive 
interventions, based on the individual needs of YLH. Although addressing comorbid issues may be costlier initially, it may have substantial savings in terms of reducing the probability of
HIV transmission among YLH, which is an important individual-level and public health outcome.

\section{Acknowledgments}

The Comprehensive Adolescent Research and Engagement Studies (CARES) is a program project grant funded by the Adolescent Medicine Trials Network for HIV/AIDS Interventions (ATN) at the National Institutes of Health (U19HD089886). The Eunice Kennedy National Institute of Child Health and Human Development (NICHD) is the primary funder of this network, with support of the National Institute of Mental Health (NIMH), National Institute of Drug Abuse (NIDA), and National Institute on Minority Health and Health Disparities (NIMHD).

In addition to the authors, the following members of the ATN CARES Team made contributions to this study protocol: M Isabel Fernandez, Jeffrey D Klausner, Sung-Jae Lee, Maryann Koussa, Manuel Ocasio, W Scott Comulada, Robert Weiss, Ronald Brookmeyer, Wenze Tang, Karin Nielsen-Saines, Yvonne Bryson, Tara Kerin, Chelsea Shannon, Ruth Cortado, Kate Mitchell, Norweeta Milburn, Cathy Reback, and Marguerita Lightfoot.

\section{Conflicts of Interest}

None declared.

\section{References}

1. Zanoni BC, Mayer KH. The adolescent and young adult HIV cascade of care in the United States: exaggerated health disparities. AIDS Patient Care STDS 2014 Mar;28(3):128-135 [FREE Full text] [doi: 10.1089/apc.2013.0345] [Medline: 24601734]

2. Centers for Disease Control Prevention. HIV among youth. 2017. URL: http://www.cdc.gov/hiv/group/age/youth/[WebCite Cache ID 6vU9ArZvf]

3. Centers for Disease Control Prevention. CDC vital signs: HIV among youth in the US. 2012. URL: https://www.cdc.gov/ vitalsigns/hivamongyouth/index.html[WebCite Cache ID 6vU7YtpQD]

4. Kim SH, Gerver SM, Fidler S, Ward H. Adherence to antiretroviral therapy in adolescents living with HIV: systematic review and meta-analysis. AIDS 2014 Aug 24;28(13):1945-1956 [FREE Full text] [doi: 10.1097/QAD.0000000000000316] [Medline: 24845154]

5. Kurth AE, Celum C, Baeten JM, Vermund SH, Wasserheit JN. Combination HIV prevention: significance, challenges, and opportunities. Curr HIV/AIDS Rep 2011 Mar;8(1):62-72 [FREE Full text] [doi: 10.1007/s11904-010-0063-3] [Medline: 20941553]

6. Skarbinski J, Rosenberg E, Paz-Bailey G, Hall HI, Rose CE, Viall AH, et al. Human immunodeficiency virus transmission at each step of the care continuum in the United States. JAMA Intern Med 2015 Apr;175(4):588-596. [doi: 10.1001/jamainternmed.2014.8180] [Medline: 25706928]

7. Centers for Disease Control Prevention, Human Resources and Services Administration, National Institutes of Health, American Academy of HIV Medicine, Association of Nurses in AIDS Care, International Association of Providers of AIDS Care, National Minority AIDS Council, Urban Coalition for HIV/AIDS Prevention Services. Recommendations for HIV prevention with adults and adolescents with HIV in the United States. 2014. URL: https://stacks.cdc.gov/view/cdc/ 44064[WebCite Cache ID 6vYgtAQtl]

8. Mitchell MM, Nguyen TQ, Isenberg SR, Maragh-Bass AC, Keruly J, Knowlton AR. Psychosocial and service use correlates of health-related quality of life among a vulnerable population living with HIV/AIDS. AIDS Behav 2017 Jun;21(6):1580-1587 [FREE Full text] [doi: 10.1007/s10461-016-1589-1] [Medline: 27787675]

9. Kahana SY, Jenkins RA, Bruce D, Fernandez MI, Hightow-Weidman LB, Bauermeister JA, Adolescent Medicine Trials Network for HIV/AIDS Interventions. Structural determinants of antiretroviral therapy use, HIV care attendance, and viral suppression among adolescents and young adults living with HIV. PLoS One 2016;11(4):e0151106 [FREE Full text] [doi: 10.1371/journal.pone.0151106] [Medline: 27035905]

10. AIDSVu. 2018. Understanding HIV where you live URL: https://aidsvu.org/ [accessed 2018-03-30] [WebCite Cache ID 6yJ8dQddd]

11. Centers for Disease Control Prevention. HIV among gay and bisexual men. 2017. URL: https://www.cdc.gov/hiv/pdf/group/ msm/cdc-hiv-msm.pdf[WebCite Cache ID 6vU7oe4kf]

12. Rotheram MJ, Fernandez MI, Lee SJ, Abdalian SE, Kozina L, Koussa M, Adolescent Medicine Trials Network (ATN) CARES Team. Strategies to Treat and Prevent HIV in the United States for Adolescents and Young Adults: Protocol for a Mixed-Methods Study. JMIR Res Protoc 2019 Jan 21;8(1):e10759 [FREE Full text] [doi: 10.2196/10759] [Medline: 30664482] 
13. Gardner EM, McLees MP, Steiner JF, Del Rio C, Burman WJ. The spectrum of engagement in HIV care and its relevance to test-and-treat strategies for prevention of HIV infection. Clin Infect Dis 2011 Mar;52(6):793-800 [FREE Full text] [doi: 10.1093/cid/ciq243] [Medline: 21367734]

14. Paterson DL, Swindells S, Mohr J, Brester M, Vergis EN, Squier C, et al. Adherence to protease inhibitor therapy and outcomes in patients with HIV infection. Ann Intern Med 2000 Jul;133(1):21-30. [Medline: 10877736]

15. Viswanathan S, Detels R, Mehta SH, Macatangay BJC, Kirk GD, Jacobson LP. Level of adherence and HIV RNA suppression in the current era of highly active antiretroviral therapy (HAART). AIDS Behav 2015 Apr;19(4):601-611 [FREE Full text] [doi: 10.1007/s10461-014-0927-4] [Medline: 25342151]

16. Murphy DA, Wilson CM, Durako SJ, Muenz LR, Belzer M, Adolescent Medicine HIV/AIDS Research Network. Antiretroviral medication adherence among the REACH HIV-infected adolescent cohort in the USA. AIDS Care 2001 Feb;13(1):27-40. [doi: 10.1080/09540120020018161] [Medline: 11177463]

17. Farmer C, Yehia BR, Fleishman JA, Rutstein R, Mathews WC, Nijhawan A, et al. Factors associated with retention among non-perinatally HIV-infected youth in the HIV Research Network. J Pediatric Infect Dis Soc 2016 Mar;5(1):39-46 [FREE Full text] [doi: 10.1093/jpids/piu102] [Medline: 26908490]

18. Murphy DA, Belzer M, Durako SJ, Sarr M, Wilson CM, Muenz LR, Adolescent Medicine HIV/AIDS Research Network. Longitudinal antiretroviral adherence among adolescents infected with human immunodeficiency virus. Arch Pediatr Adolesc Med 2005 Aug;159(8):764-770. [doi: 10.1001/archpedi.159.8.764] [Medline: 16061785]

19. Hall HI, Holtgrave DR, Maulsby C. HIV transmission rates from persons living with HIV who are aware and unaware of their infection. AIDS 2012 Apr 24;26(7):893-896. [doi: 10.1097/QAD.0b013e328351f73f] [Medline: 22313960]

20. Belzer ME, Fuchs DN, Luftman GS, Tucker DJ. Antiretroviral adherence issues among HIV-positive adolescents and young adults. J Adolesc Health 1999 Nov;25(5):316-319. [Medline: 10551660]

21. Ferrand R, Ford N, Kranzer K. Maximising the benefits of home-based HIV testing. Lancet HIV 2015 Jan;2(1):e4-e5. [doi: 10.1016/S2352-3018(14)00039-3] [Medline: 26424234]

22. Garofalo R, Kuhns LM, Hotton A, Johnson A, Muldoon A, Rice D. A randomized controlled trial of personalized text message reminders to promote medication adherence among HIV-positive adolescents and young adults. AIDS Behav 2016 May;20(5):1049-1059. [doi: 10.1007/s10461-015-1192-x] [Medline: 26362167]

23. Yard SS, Huh D, King KM, Simoni JM. Patient-level moderators of the efficacy of peer support and pager reminder interventions to promote antiretroviral adherence. AIDS Behav 2011 Nov;15(8):1596-1604 [FREE Full text] [doi: 10.1007/s10461-011-0001-4] [Medline: 21739291]

24. Maslow AH. Motivation and personality. New York, NY: Harper and Row; 1970.

25. Barroso J, Leblanc NM, Flores D. It's not just the pills: a qualitative meta-synthesis of HIV antiretroviral adherence research. J Assoc Nurses AIDS Care 2017;28(4):462-478. [doi: 10.1016/j.jana.2017.02.007] [Medline: 28286006]

26. Chandwani S, Koenig LJ, Sill AM, Abramowitz S, Conner LC, D'Angelo L. Predictors of antiretroviral medication adherence among a diverse cohort of adolescents with HIV. J Adolesc Health 2012 Sep;51(3):242-251. [doi:

10.1016/j.jadohealth.2011.12.013] [Medline: 22921134]

27. Fields EL, Bogart LM, Thurston IB, Hu CH, Skeer MR, Safren SA, et al. Qualitative comparison of barriers to antiretroviral medication adherence among perinatally and behaviorally HIV-infected youth. Qual Health Res 2017 Jul;27(8):1177-1189 [FREE Full text] [doi: 10.1177/1049732317697674] [Medline: 28682737]

28. Zatzick D, Jurkovich G, Rivara FP, Russo J, Wagner A, Wang J, et al. A randomized stepped care intervention trial targeting posttraumatic stress disorder for surgically hospitalized injury survivors. Ann Surg 2013 Mar;257(3):390-399 [FREE Full text] [doi: 10.1097/SLA.0b013e31826bc313] [Medline: 23222034]

29. Stoop CH, Nefs G, Pommer AM, Pop VJM, Pouwer F. Effectiveness of a stepped care intervention for anxiety and depression in people with diabetes, asthma or COPD in primary care: a randomized controlled trial. J Affect Disord 2015 Sep 15;184:269-276. [doi: 10.1016/j.jad.2015.05.063] [Medline: 26118755]

30. Salloum A, Robst J, Scheeringa MS, Cohen JA, Wang W, Murphy TK, et al. Step one within stepped care trauma-focused cognitive behavioral therapy for young children: a pilot study. Child Psychiatry Hum Dev 2014 Feb;45(1):65-77 [FREE Full text] [doi: 10.1007/s10578-013-0378-6] [Medline: 23584728]

31. Mimiaga MJ, Kuhns LM, Biello KB, Olson J, Hoehnle S, Santostefano CM, et al. Positive STEPS - a randomized controlled efficacy trial of an adaptive intervention for strengthening adherence to antiretroviral HIV treatment among youth: study protocol. BMC Public Health 2018 Jul 13;18(1). [doi: 10.1186/s12889-018-5815-9] [Medline: 30001703]

32. Kanfer FH. Self-monitoring: methodological limitations and clinical applications. J of Consulting and Clin Psych 1970;35(2):148-152. [doi: 10.1037/h0029874]

33. Sherman E, Clauson KA, Elrod S, Eckardt P, Alkhateeb F, Jacobs R. Patient perceptions of text messaging to improve antiretroviral therapy adherence: a qualitative study of patients in a Ryan White Clinic. J Int Assoc Provid AIDS Care 2018;17:2325958218759209. [doi: 10.1177/2325958218759209] [Medline: 29473483]

34. Horvath T, Azman H, Kennedy GE, Rutherford GW. Mobile phone text messaging for promoting adherence to antiretroviral therapy in patients with HIV infection. Cochrane Database Syst Rev 2012;3:CD009756. [doi: 10.1002/14651858.CD009756] [Medline: 22419345] 
35. Dowshen N, Kuhns LM, Johnson A, Holoyda BJ, Garofalo R. Improving adherence to antiretroviral therapy for youth living with HIV/AIDS: a pilot study using personalized, interactive, daily text message reminders. J Med Internet Res 2012;14(2):e51 [FREE Full text] [doi: 10.2196/jmir.2015] [Medline: 22481246]

36. Mbuagbaw L, van der Kop ML, Lester RT, Thirumurthy H, Pop-Eleches C, Smieja M, et al. Mobile phone text messages for improving adherence to antiretroviral therapy (ART): a protocol for an individual patient data meta-analysis of randomised trials. BMJ Open 2013;3(5) [FREE Full text] [doi: 10.1136/bmjopen-2013-002954] [Medline: 23793704]

37. Mbuagbaw L, Mursleen S, Lytvyn L, Smieja M, Dolovich L, Thabane L. Mobile phone text messaging interventions for HIV and other chronic diseases: an overview of systematic reviews and framework for evidence transfer. BMC Health Serv Res 2015 Jan 22;15:33 [FREE Full text] [doi: 10.1186/s12913-014-0654-6] [Medline: 25609559]

38. Dunbar PJ, Madigan D, Grohskopf LA, Revere D, Woodward J, Minstrell J, et al. A two-way messaging system to enhance antiretroviral adherence. J Am Med Inform Assoc 2003;10(1):11-15 [FREE Full text] [Medline: 12509353]

39. Pop-Eleches C, Thirumurthy H, Habyarimana JP, Zivin JG, Goldstein MP, de Walque D, et al. Mobile phone technologies improve adherence to antiretroviral treatment in a resource-limited setting: a randomized controlled trial of text message reminders. AIDS 2011 Mar 27;25(6):825-834 [FREE Full text] [doi: 10.1097/QAD.0b013e32834380c1] [Medline: 21252632]

40. Lewis MA, Uhrig JD, Bann CM, Harris JL, Furberg RD, Coomes C, et al. Tailored text messaging intervention for HIV adherence: a proof-of-concept study. Health Psychol 2013 Mar;32(3):248-253. [doi: 10.1037/a0028109] [Medline: 22545972]

41. King E, Kinvig K, Steif J, Qiu AQ, Maan EJ, Albert AY, et al. Mobile text messaging to improve medication adherence and viral load in a vulnerable Canadian population living with human immunodeficiency virus: a repeated measures study. J Med Internet Res 2017 Jun 01;19(6):e190 [FREE Full text] [doi: 10.2196/jmir.6631] [Medline: 28572079]

42. Levine D, McCright J, Dobkin L, Woodruff AJ, Klausner JD. SEXINFO: a sexual health text messaging service for San Francisco youth. Am J Public Health 2008 Mar;98(3):393-395. [doi: 10.2105/AJPH.2007.110767] [Medline: 18235068]

43. Reback CJ, Grant DL, Fletcher JB, Branson CM, Shoptaw S, Bowers JR, et al. Text messaging reduces HIV risk behaviors among methamphetamine-using men who have sex with men. AIDS Behav 2012 Oct;16(7):1993-2002 [FREE Full text] [doi: 10.1007/s10461-012-0200-7] [Medline: 22610370]

44. Reback CJ, Fletcher JB, Shoptaw S, Mansergh G. Exposure to theory-driven text messages is associated with HIV risk reduction among methamphetamine-using men who have sex with men. AIDS Behav 2015 Jun;19 Suppl 2:130-141. [doi: 10.1007/s10461-014-0985-7] [Medline: 25563501]

45. Reback CJ, Fletcher JB, Swendeman D. Associations between sociodemographic characteristics and sexual risk behaviors among methamphetamine-using men who have sex with men. Subst Use Misuse 2018 Feb 12:1-8. [doi:

10.1080/10826084.2018.1436566] [Medline: 29432057]

46. Cornelius JB, Dmochowski J, Boyer C, St Lawrence J, Lightfoot M, Moore M. Text-messaging-enhanced HIV intervention for African American adolescents: a feasibility study. J Assoc Nurses AIDS Care 2013;24(3):256-267 [FREE Full text] [doi: 10.1016/j.jana.2012.06.005] [Medline: 23122907]

47. Kanfer F, Gaelick-Buys L. Self-management Methods. Elmsford, NY: Pergamon Press; 1991:0080378935.

48. Bandura A. Social cognitive theory of self-regulation. Organizational Behavior and Human Decision Processes 1991 Dec;50(2):248-287. [doi: 10.1016/0749-5978(91)90022-L]

49. Swendeman D, Arnold E, Harris D, Rotheram-Borus MJ, Team TASC. What strategies are enough to protect youth from HIV: automated messaging, weekly behavioral monitoring, peer social media networks, or interpersonal coaching? (preprint). JMIR Research Protocols 2019 [FREE Full text] [doi: 10.2196/preprints.11165]

50. Yehia BR, Stewart L, Momplaisir F, Mody A, Holtzman CW, Jacobs LM, et al. Barriers and facilitators to patient retention in HIV care. BMC Infect Dis 2015 Jun 28;15:246 [FREE Full text] [doi: 10.1186/s12879-015-0990-0] [Medline: 26123158]

51. Rajabiun S, Mallinson RK, McCoy K, Coleman S, Drainoni M, Rebholz C, et al. "Getting back on track": the role of outreach interventions in engaging and retaining people living with HIV/AIDS in medical care. AIDS patient care STDs 2007;21 Suppl 1:S20-S29. [doi: 10.1089/apc.2007.9990] [Medline: 17563286]

52. Christopoulos KA, Massey AD, Lopez AM, Geng EH, Johnson MO, Pilcher CD, et al. "Taking a half day at a time": patient perspectives and the HIV engagement in care continuum. AIDS Patient Care STDS 2013 Apr;27(4):223-230 [FREE Full text] [doi: 10.1089/apc.2012.0418] [Medline: 23565926]

53. Rice E, Milburn NG, Rotheram-Borus MJ. Pro-social and problematic social network influences on HIV/AIDS risk behaviours among newly homeless youth in Los Angeles. AIDS Care 2007 May;19(5):697-704 [FREE Full text] [doi: 10.1080/09540120601087038] [Medline: 17505933]

54. DiClemente CC, Nidecker M, Bellack AS. Motivation and the stages of change among individuals with severe mental illness and substance abuse disorders. J Subst Abuse Treat 2008 Jan;34(1):25-35. [doi: 10.1016/j.jsat.2006.12.034] [Medline: $17574798]$

55. Stellefson M, Dipnarine K, Stopka C. The chronic care model and diabetes management in US primary care settings: a systematic review. Prev Chronic Dis 2013;10:E26 [FREE Full text] [doi: 10.5888/pcd10.120180] [Medline: 23428085]

56. Boothroyd RI, Fisher EB. Peers for progress: promoting peer support for health around the world. Fam Pract 2010 Jun;27 Suppl 1:i62-i68. [doi: 10.1093/fampra/cmq017] [Medline: 20483801] 
57. Simoni JM, Huh D, Frick PA, Pearson CR, Andrasik MP, Dunbar PJ, et al. Peer support and pager messaging to promote antiretroviral modifying therapy in Seattle: a randomized controlled trial. J Acquir Immune Defic Syndr 2009 Dec 1;52(4):465-473 [FREE Full text] [Medline: 19911481]

58. Eysenbach G, Powell J, Englesakis M, Rizo C, Stern A. Health related virtual communities and electronic support groups: systematic review of the effects of online peer to peer interactions. BMJ 2004 May 15;328(7449):1166 [FREE Full text] [doi: 10.1136/bmj.328.7449.1166] [Medline: 15142921]

59. Fisher EB, Boothroyd RI, Coufal MM, Baumann LC, Mbanya JC, Rotheram-Borus MJ, et al. Peer support for self-management of diabetes improved outcomes in international settings. Health Aff (Millwood) 2012 Jan;31(1):130-139 [FREE Full text] [doi: 10.1377/hlthaff.2011.0914] [Medline: 22232103]

60. Brown JL, Vanable PA. Cognitive-behavioral stress management interventions for persons living with HIV: a review and critique of the literature. Ann Behav Med 2008 Feb;35(1):26-40 [FREE Full text] [doi: 10.1007/s12160-007-9010-y] [Medline: 18347902]

61. Steinberg L, Morris AS. Adolescent development. Annu Rev Psychol 2001;52:83-110. [doi: 10.1146/annurev.psych.52.1.83] [Medline: 11148300$]$

62. Viner RM, Ozer EM, Denny S, Marmot M, Resnick M, Fatusi A, et al. Adolescence and the social determinants of health. Lancet 2012 Apr 28;379(9826):1641-1652. [doi: 10.1016/S0140-6736(12)60149-4] [Medline: 22538179]

63. McFall RM, Lillesand DB. Behavior rehearsal with modeling and coaching in assertion training. J Abnorm Psychol 1971 Jun;77(3):313-323. [Medline: 5556941]

64. Gresham FM, Nagle RJ. Social skills training with children: responsiveness to modeling and coaching as a function of peer orientation. J Consult Clin Psychol 1980 Dec;48(6):718-729. [Medline: 7440828]

65. Eells MA. Interventions with alcoholics and their families. Nurs Clin North Am 1986 Sep;21(3):493-504. [Medline: 3638703]

66. Feldman DC, Lankau MJ. Executive coaching: a review and agenda for future research. Journal of Management 2016 Jul;31(6):829-848. [doi: 10.1177/0149206305279599] [Medline: 22973420]

67. Butterworth SW, Linden A, McClay W. Health coaching as an intervention in health management programs. Disease Management \& Health Outcomes 2007;15(5):299-307. [doi: 10.2165/00115677-200715050-00004]

68. Sullivan M, Langford DJ, Davies PS, Tran C, Vilardaga R, Cheung G, et al. A controlled pilot trial of PainTracker Self-Manager, a web-based platform combined with patient coaching, to support patients' self-management of chronic pain. J Pain 2018 Mar 29. [doi: 10.1016/j.jpain.2018.03.009] [Medline: 29605691]

69. Painter SL, Ahmed R, Kushner RF, Hill JO, Lindquist R, Brunning S, et al. Expert coaching in weight loss: retrospective analysis. J Med Internet Res 2018 Mar 13;20(3):e92 [FREE Full text] [doi: 10.2196/jmir.9738] [Medline: 29535082]

70. Haug NA, Sorensen JL, Gruber VA, Lollo N, Roth G. HAART adherence strategies for methadone clients who are HIV-positive: a treatment manual for implementing contingency management and medication coaching. Behav Modif 2006 Nov;30(6):752-781. [doi: 10.1177/0145445506288229] [Medline: 17050764$]$

71. Hill B, Richardson B, Skouteris H. Do we know how to design effective health coaching interventions: a systematic review of the state of the literature. Am J Health Promot 2015;29(5):e158-e168. [doi: 10.4278/ajhp.130510-LIT-238] [Medline: 24720388]

72. Wilson IB, Lee Y, Michaud J, Fowler FJ, Rogers WH. Validation of a new three-item self-report measure for medication adherence. AIDS Behav 2016 Nov;20(11):2700-2708 [FREE Full text] [doi: 10.1007/s10461-016-1406-x] [Medline: 27098408]

73. Lu M, Safren SA, Skolnik PR, Rogers WH, Coady W, Hardy H, et al. Optimal recall period and response task for self-reported HIV medication adherence. AIDS Behav 2008 Jan;12(1):86-94. [doi: 10.1007/s10461-007-9261-4] [Medline: 17577653]

74. Bush K, Kivlahan DR, McDonell MB, Fihn SD, Bradley KA. The AUDIT alcohol consumption questions (AUDIT-C): an effective brief screening test for problem drinking. Ambulatory Care Quality Improvement Project (ACQUIP). Alcohol Use Disorders Identification Test. Arch Intern Med 1998 Sep 14;158(16):1789-1795. [Medline: 9738608]

75. Ware J, Kosinski M, Keller SD. A 12-Item Short-Form Health Survey: construction of scales and preliminary tests of reliability and validity. Med Care 1996 Mar;34(3):220-233. [Medline: $\underline{8628042]}$

76. Spitzer RL, Johnson JG. The Patient Health Questionnaire-Adolescent Version. New York: Biometrics Research Unit, New York State Psychiatric Institute; 1995.

77. Spitzer RL, Kroenke K, Williams JBW, Löwe B. A brief measure for assessing generalized anxiety disorder: the GAD-7. Arch Intern Med 2006 May 22;166(10):1092-1097. [doi: 10.1001/archinte.166.10.1092] [Medline: 16717171]

78. Dowshen N, Kuhns LM, Gray C, Lee S, Garofalo R. Feasibility of interactive text message response (ITR) as a novel, real-time measure of adherence to antiretroviral therapy for HIV+ youth. AIDS Behav 2013 Jul;17(6):2237-2243. [doi: 10.1007/s10461-013-0464-6] [Medline: 23546844]

79. Google Play. 2018. Time It URL: https://play.google.com/store/apps/details?id=com.cubestudio.timeit\&hl=en [accessed 2019-01-27] [WebCite Cache ID 6y8mqT0u2]

80. Swendeman D, Ramanathan N, Baetscher L, Medich M, Scheffler A, Comulada WS, et al. Smartphone self-monitoring to support self-management among people living with HIV: perceived benefits and theory of change from a mixed-methods 
randomized pilot study. J Acquir Immune Defic Syndr 2015 May 01;69 Suppl 1:S80-S91 [FREE Full text] [doi: 10.1097/QAI.0000000000000570] [Medline: 25867783]

81. Swendeman D, Rotheram-Borus MJ. Innovation in sexually transmitted disease and HIV prevention: internet and mobile phone delivery vehicles for global diffusion. Curr Opin Psychiatry 2010 Mar;23(2):139-144 [FREE Full text] [doi: 10.1097/YCO.0b013e328336656a] [Medline: 20087189]

82. Swendeman D, Comulada WS, Ramanathan N, Lazar M, Estrin D. Reliability and validity of daily self-monitoring by smartphone application for health-related quality-of-life, antiretroviral adherence, substance use, and sexual behaviors among people living with HIV. AIDS Behav 2015 Feb;19(2):330-340 [FREE Full text] [doi: 10.1007/s10461-014-0923-8] [Medline: 25331266]

83. Swendeman D, Jana S, Ray P, Mindry D, Das M, Bhakta B. Development and pilot testing of daily Interactive Voice Response (IVR) calls to support antiretroviral adherence in India: a mixed-methods pilot study. AIDS Behav 2015 Jun;19 Suppl 2:142-155 [FREE Full text] [doi: 10.1007/s10461-014-0983-9] [Medline: 25638037]

84. Prado G, Pantin H, Schwartz SJ, Lupei NS, Szapocznik J. Predictors of engagement and retention into a parent-centered, ecodevelopmental HIV preventive intervention for Hispanic adolescents and their families. J Pediatr Psychol 2006 Oct;31(9):874-890. [doi: 10.1093/jpepsy/jsj046] [Medline: 16049264$]$

85. Izumi BT, Schulz AJ, Mentz G, Israel BA, Sand SL, Reyes AG, et al. Leader behaviors, group cohesion, and participation in a walking group program. Am J Prev Med 2015 Jul;49(1):41-49 [FREE Full text] [doi: 10.1016/j.amepre.2015.01.019] [Medline: 26094226]

86. Merson MH, O'Malley J, Serwadda D, Apisuk C. The history and challenge of HIV prevention. Lancet 2008 Aug 09;372(9637):475-488. [doi: 10.1016/S0140-6736(08)60884-3] [Medline: 18687461$]$

87. Rotheram-Borus MJ, Swendeman D, Flannery D, Rice E, Adamson DM, Ingram B. Common factors in effective HIV prevention programs. AIDS Behav 2009 Jun;13(3):399-408 [FREE Full text] [doi: 10.1007/s10461-008-9464-3] [Medline: $\underline{18830813}$ ]

88. Rotheram-Borus MJ, Swendeman D, Lee SJ, Li L, Amani B, Nartey M. Interventions for families affected by HIV. Transl Behav Med 2011 Jun;1(2):313-326 [FREE Full text] [doi: 10.1007/s13142-011-0043-1] [Medline: 21765881]

89. Rapp CA, Goscha RJ. The strengths model: A recovery-oriented approach to mental health services. New York: Oxford University Press; 2012.

90. Arnold EM, Walsh AK, Oldham MS, Rapp CA. Strengths-based case management: implementation with high-risk youth. Families in Society 2018 May 03;88(1):86-94. [doi: 10.1606/1044-3894.3595]

91. Craw JA, Gardner LI, Marks G, Rapp RC, Bosshart J, Duffus WA, et al. Brief strengths-based case management promotes entry into HIV medical care: results of the antiretroviral treatment access study-II. J Acquir Immune Defic Syndr 2008 Apr 15;47(5):597-606. [doi: 10.1097/QAI.0b013e3181684c51] [Medline: 18285714]

92. Kral AH, Lambdin BH, Comfort M, Powers C, Cheng H, Lopez AM, et al. A strengths-based case management intervention to reduce HIV viral load among people who use drugs. AIDS Behav 2018 Jan;22(1):146-153. [doi:

10.1007/s10461-017-1903-6] [Medline: 28916898]

93. Surratt HL, O'Grady C, Kurtz SP, Levi-Minzi MA, Chen M. Outcomes of a behavioral intervention to reduce HIV risk among drug-involved female sex workers. AIDS Behav 2014 Apr;18(4):726-739 [FREE Full text] [doi: 10.1007/s10461-014-0723-1] [Medline: 24558098]

94. Corsi KF, Lehman WE, Min SJ, Lance SP, Speer N, Booth RE, et al. The Feasibility of interventions to reduce HIV risk and drug use among heterosexual methamphetamine users. J AIDS Clin Res 2012 Jun 04;S1(10) [FREE Full text] [doi: 10.4172/2155-6113.S1-010] [Medline: 23493796]

95. Rotheram-Borus MJ, Swendeman D, Becker KD. Adapting evidence-based interventions using a common theory, practices, and principles. J Clin Child Adolesc Psychol 2014;43(2):229-243 [FREE Full text] [doi: 10.1080/15374416.2013.836453] [Medline: 24079747]

96. Chorpita BF, Daleiden EL. Mapping evidence-based treatments for children and adolescents: application of the distillation and matching model to 615 treatments from 322 randomized trials. J Consult Clin Psychol 2009 Jun;77(3):566-579. [doi: 10.1037/a0014565] [Medline: 19485596]

97. Rotheram-Borus MJ, Swendeman D, Rotheram-Fuller E, Youssef MK. Family coaching as a delivery modality for evidence-based prevention programs. Clin Child Psychol Psychiatry 2018 Jan;23(1):96-109. [doi: 10.1177/1359104517721958] [Medline: 28849666]

98. Morin SF, Steward WT, Charlebois ED, Remien RH, Pinkerton SD, Johnson MO, et al. Predicting HIV transmission risk among HIV-infected men who have sex with men: findings from the healthy living project. J Acquir Immune Defic Syndr 2005 Oct 01;40(2):226-235. [Medline: 16186742]

99. Weiss R. Modeling longitudinal data. In: Modeling Longitudinal Data (Springer Texts In Statistics). Berlin, Germany: Springer; 2019.

100. Lightfoot M, Rotheram-Borus MJ, Comulada WS, Reddy VS, Duan N. Efficacy of brief interventions in clinical care settings for persons living with HIV. J Acquir Immune Defic Syndr 2010 Mar;53(3):348-356. [doi:

10.1097/QAI.0b013e3181c429b3] [Medline: 19996978] 
101. Comulada WS. Model specification and bootstrapping for multiply imputed data: an application to count models for the frequency of alcohol use. Stata J 2015 Jun;15(3):833-844 [FREE Full text] [Medline: 26973439]

102. Comulada WS, Rotheram-Borus MJ, Pequegnat W, Weiss RE, Desmond KA, Arnold EM, et al. Relationships over time between mental health symptoms and transmission risk among persons living with HIV. Psychol Addict Behav 2010 Mar;24(1):109-118 [FREE Full text] [doi: 10.1037/a0018190] [Medline: 20307117]

103. Selig J, Preacher KJ. Mediation models for longitudinal data in developmental research. Research in Human Development. (2-3) 2009;6:144-164. [doi: 10.1080/1542700902911247]

104. Gold M. Panel on cost-effectiveness in health and medicine. Med Care 1996 Dec;34(12 Suppl):DS197-DS199. [Medline: 8969326]

105. Russell LB, Gold MR, Siegel JE, Daniels N, Weinstein MC. The role of cost-effectiveness analysis in health and medicine. Panel on Cost-Effectiveness in Health and Medicine. JAMA 1996 Oct 09;276(14):1172-1177. [Medline: 8827972]

106. Hintze J. NCSS Statistical Software - PASS Sample Size. 2008. Sample Size \& Power URL: $\underline{\text { https://www.ncss.com/software/ }}$ pass/ [accessed 2018-04-10] [WebCite Cache ID 6yZzpwASq]

107. Complete listing of LRC best practices. Centers for Disease Control Prevention URL: https://www.cdc.gov/hiv/research/ interventionresearch/compendium/lrc/completelist.html [accessed 2019-01-27] [WebCite Cache ID 737VSWW0z]

108. HIV cost-effectiveness. Centers for Disease Control Prevention URL: https://www.cdc.gov/hiv/programresources/guidance/ costeffectiveness/index.html [accessed 2019-01-27] [WebCite Cache ID 6y8mUxvKk]

109. Katon W, Unützer J, Fan MY, Williams Jr JW, Schoenbaum M, Lin EHB, et al. Cost-effectiveness and net benefit of enhanced treatment of depression for older adults with diabetes and depression. Diabetes Care 2006 Feb;29(2):265-270. [Medline: 16443871$]$

110. Meeuwissen JAC, Feenstra TL, Smit F, Blankers M, Spijker J, Bockting CLH, et al. The cost-utility of stepped-care algorithms according to depression guideline recommendations - results of a state-transition model analysis. J Affect Disord 2019 Jan 01;242:244-254. [doi: 10.1016/j.jad.2018.08.024] [Medline: 30216769]

111. Gonzalez JS, Batchelder AW, Psaros C, Safren SA. Depression and HIV/AIDS treatment nonadherence: a review and meta-analysis. J Acquir Immune Defic Syndr 2011 Oct 01;58(2):181-187 [FREE Full text] [doi: 10.1097/QAI.0b013e31822d490a] [Medline: 21857529]

\author{
Abbreviations \\ AMMI: automated messaging and monitoring intervention \\ ART: antiretroviral therapy \\ CER: cost-effectiveness ratio \\ EBI: evidence-based intervention \\ GBTY: gay, bisexual, and transgender youth \\ HIPAA: Health Insurance Portability and Accountability Act \\ MLM: multilevel models \\ PHQ-A: Patient Health Questionnaire for adolescents \\ RCT: randomized control trial \\ RDT: rapid diagnostic tests \\ SMS: short message service \\ STI: sexually transmitted infection \\ YLH: youth living with HIV
}

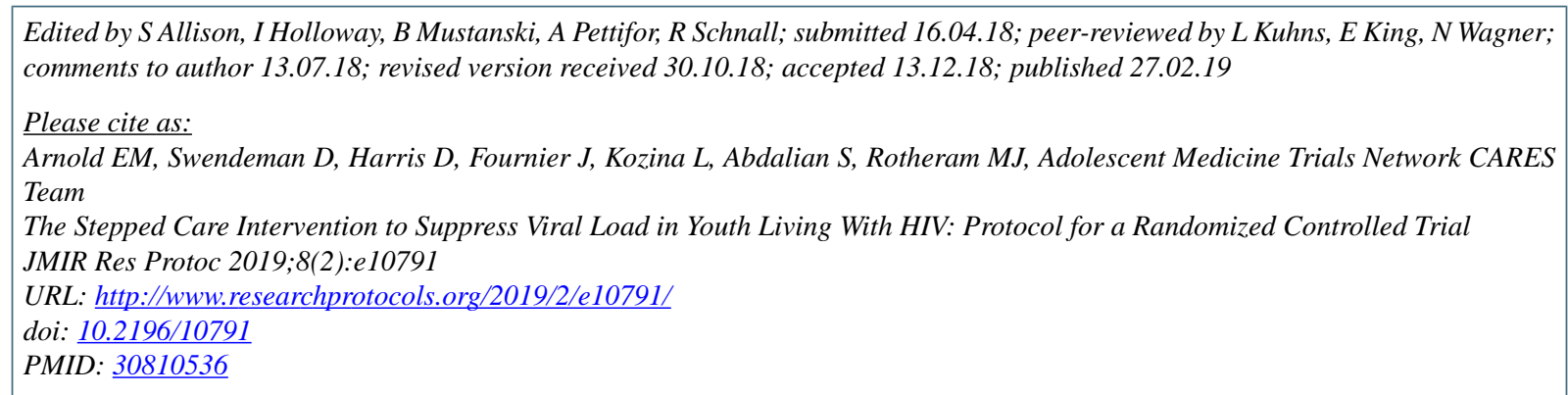

CElizabeth Mayfield Arnold, Dallas Swendeman, Danielle Harris, Jasmine Fournier, Leslie Kozina, Susan Abdalian, Mary Jane Rotheram, Adolescent Medicine Trials Network CARES Team. Originally published in JMIR Research Protocols 
(http://www.researchprotocols.org), 27.02.2019. This is an open-access article distributed under the terms of the Creative Commons Attribution License (https://creativecommons.org/licenses/by/4.0/), which permits unrestricted use, distribution, and reproduction in any medium, provided the original work, first published in JMIR Research Protocols, is properly cited. The complete bibliographic information, a link to the original publication on http://www.researchprotocols.org, as well as this copyright and license information must be included. 